\title{
CLINKPROJECT5: LOST \& FOUND
}

\author{
CLINK Collective
}

CLINKProject5: Lost \& Found was focused on the action of collaborative making by participants from the Dunedin School of Art at Otago Polytechnic and Hungry Creek Art and Craft School, Auckland. The topical issue of plastic bag use and the experience of the Auckland waterfront, a current and historical site of food gathering and sharing, sparked the use of 'the bag' as a key motif. CLINKProject5 makers placed artworks either discretely or explicitly in the vicinity of the Viaduct Harbour for audiences to find and keep. The joy of discovery was intended to draw attention to ideas about resources, consumerism and kaitiakitanga.

Since its inception in 2014, the CLINK collective's projects have played with the experience of 'disruption' or 'intervention' in the form of unannounced pop-up exhibitions in the centre of Auckland. Key driving aspects developed by the group are collaborative making, public interaction and collective publication in the journal Scope: Contemporary Research Topics (thescopes.org).

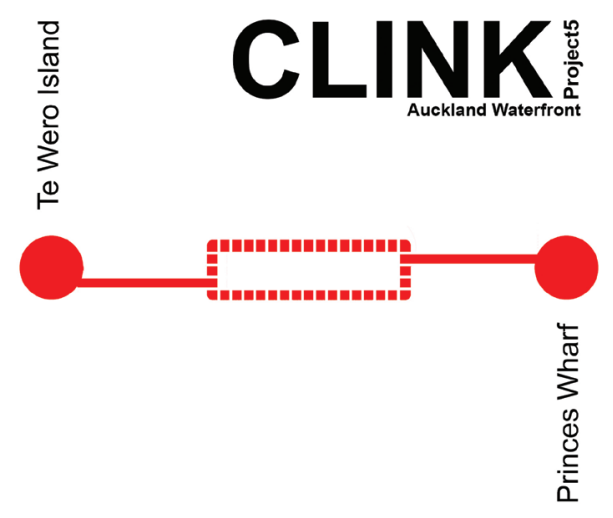

Figure I. Clink Project 5 logo.

Enticed by the motto "Come, look and see what you might find," audiences were invited to engage with CLINKProject5: Lost \& Found on Tuesday 14 August 20 I8, at the Auckland Viaduct from 12pm onwards.

\section{Participants:}

Johanna Zellmer, Gou Yuying, Anataia Wong, Michelle Wilkinson, Emma Webster, Susan Videler, Metiria Turei, Yulia Sarandov, Amelia Rothwell, Haonan Ran, Rachel O'Connell, Andrea Muggeridge, Andrew Last, Eilish Jowett, Lissy Hunt, Shane Hartdegen, Log Grigg, Andrea Daly, Yeonjoo Chung and Victoria Bell.

\section{LOCATION SCOUTING}

\section{Andrew}

Participants met as a full group for the first time at Objectspace, a Ponsonby gallery and organisation supporting the craft/object sector. To theoretically frame our aim to foster audience interaction, the group read and discussed an article by Benjamin Lignel about jewellery as a social relational practice.' A jeweller and curator, Lignel writes about contemporary jewellery's connectedness to human interaction through the processes of making, wearing and giving. 


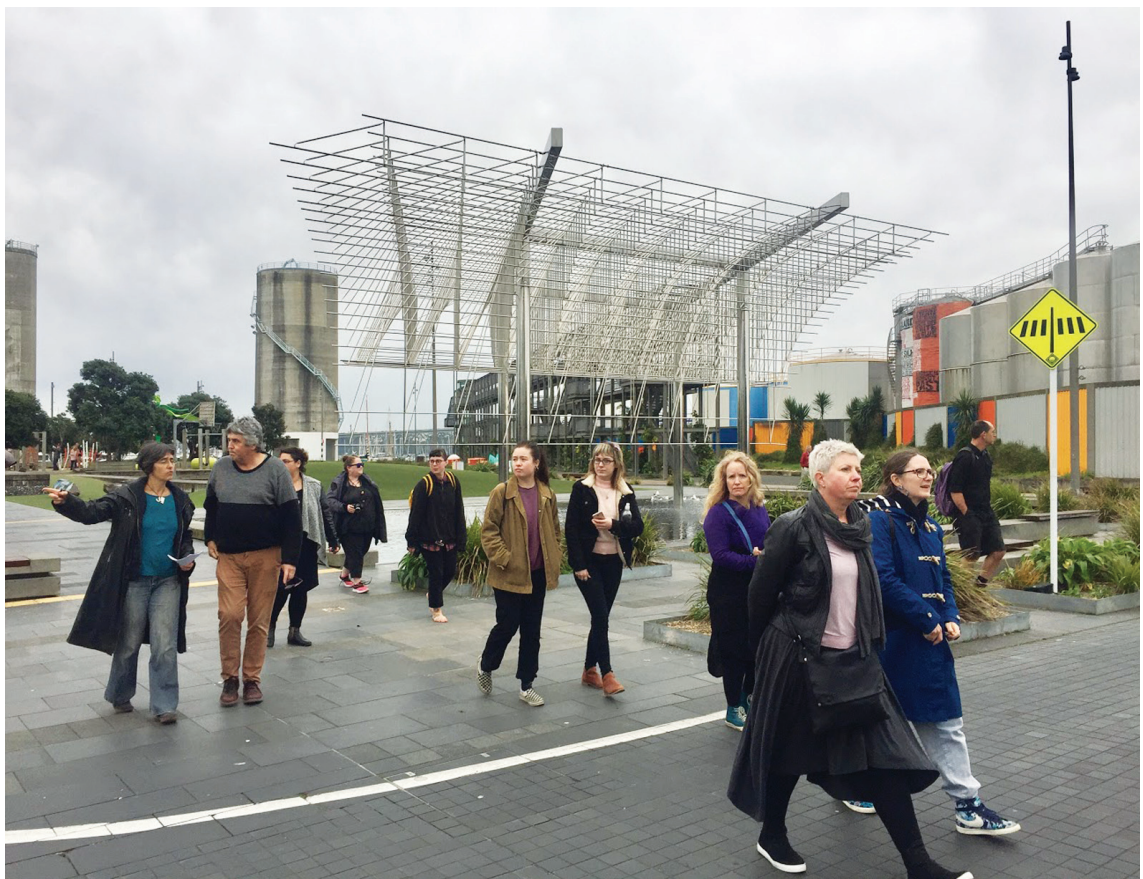

Figure 2. CLINKers scouting.

That afternoon we travelled en masse to our site, Auckland's Viaduct waterfront. The mission was to walk the length of the site from Silo Park to The Cloud, thinking about how we could make work in response to the site and how the public could interact with the location.

Familiar with the site from previous CLINK events, I had walked to the waterfront early in the mornings to get exercise and thinking time. I have been around boats and water all my life.

Ideas from scouting:

Elements in common between the Auckland waterfront and Port Chalmers in Dunedin - for example, the use of jarrah timbers, basalt stone and the boats that travel between the two ports

The contrast between superyachts and working boats

The contrast between the built and natural environments.

The key moment for me was spotting a classic wooden yacht with a sequence of marine code flags flying from mast to bow.

\section{Metiria}

We had seen a waterfront promotional video the previous day in which the importance of the fishing industry alongside the wharf development was mentioned. My attention was caught by the facade of a building near the fish market which resembled a school of fish. Yet there was no evidence of the fishing industry that brings fresh fish from wharf to market. I saw no nets or pots and only one boat that may have been a commercial fishing vessel. The absence of nets began to formulate a making plan - the net as a huge bag to carry food. 


\section{Eilish}

I was immediately interested in the empty playground and colourful, whimsical chalk drawings strewn across the pavement. I wanted to make a connection between the empty playground's inviting play areas and the colourful and odd chalk drawings. Materially, I was drawn to a broken teddy bear soft toy and colourful yarn. I took inspiration from the empty playground, imagining it to be the bottom of the ocean, with objects lost on the seafloor being taken over by sea creatures, anemones and coral.

The waterfront stimulated a conceptual exploration of ideas about food gathering (the fishing industry active at the wharves), a consequential conversation about pollution of waterways and the food chain, and topical news stories about the withdrawal of single-use plastic bags in New Zealand and Australia. The majority of CLINKers therefore decided to make artworks referencing single-use plastic bags and to place these pieces throughout the Viaduct for audiences to find.

Distinctive to CLINKProject5 was the notion of gifting. When placed on location, each artwork had a swing-tag inviting the finder to keep the work and link to the project's Facebook page for further information. As a group, we decided on the strategy of passively inviting an audience to participate via social media promotion and then offering them a means of engagement, either face-to-face on the event day or remotely via Facebook. In past CLINK events, gathering a live audience during a pop-up exhibit had provided challenges for both audience and participants.

By gifting artworks that called on rethinking our use of plastic, as well as the interconnectivity of our actions on our communities, environment and planet, these sombre themes were presented with hope. The prospective action of the gift provoked delight and optimism.

\section{PIN-SWAP}

An enduring tradition enacted when jewellers gather for conferences or meetings is the pin-swap. Each jeweller makes and anonymously wraps a brooch which is deposited in a lucky-dip container during a social event. The container is taken through the crowd and each person randomly selects a package.

\section{$\log$}

The day after the location scouting, the ClinkProject5 collective met at Hungry Creek Art and Craft School with the aim of creating pins within a three-hour period using found materials, and responding to the theme 'seams.' Although the time limit generated a sense of urgency, we were all back in the realms of the familiar - making jewellery in a workshop environment. The range of techniques and materials used produced a wide range of unique objects, each with its own story and meaning.

The collective sense of achievement generated by a group-making session was an important strategy designed to mitigate the anxiety produced by the as-yet unknown parameters of the greater project.

Since 2014 Whau Studio, located in Point Chevalier, has been hosting annual pin-swaps, an event which brings together art and community. A jewellery studio established in 20 I4, Whau is run by partners Ilse Marie Erl, Dorothy de Lautour and Laura Jer.The studio's name is derived from the plant species, Entelea arborescens, and the local river, connecting it with the history and development of the community.

There was literally the warmest of welcomes from the Whau collective when we walked in from the freezing evening winds to the toasty workshop. We gathered and chatted, exploring the workshop while we waited in anticipation for the main event.

At $6 \mathrm{pm}$, the pizzas arrived. Five metres of pure joy. The sharing of food solidified the importance of community and mutual care. 
With a bellow, the room hushed as the vessel containing our work was raised into the air. Excitement rippled through the room as the first pin was pulled. In turn, we took our prize and found each maker, taking the opportunity to discuss the work and get to know the maker.

\section{MAKING}

Making unfolded over two (long!) days at the Hungry Creek workshops - once again, a relief from the difficulties of group work resolving strategies for presentation, promotion and audience interaction for the project.

As artists, we wanted to communicate our concerns about plastic waste and the 750 million single-use plastic bags used in NZ every year. ${ }^{2}$ Our acute awareness of the impact of plastic waste on the ocean was fed by the sea of plastic material we observed in our regular walks from Hungry Creek Art and Craft School to the local bakery.

On one side of the school was a not-for-profit recycling depot with piles of white bags of plastic rubbish awaiting removal to some distant country. On the other side, a rope manufacturer had plastic mussel-growing socks dangling pink and furry from great black sacks in their driveway. And in every car park was a huge bin full of waste wood, plastic and wrapping.

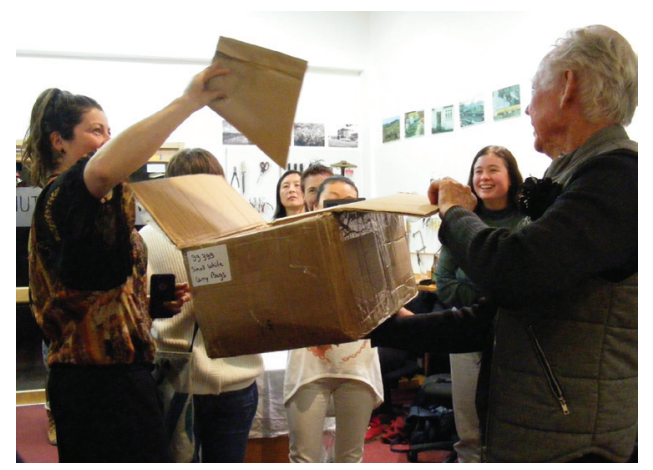

Figure 4. Pin-swap lucky dip.

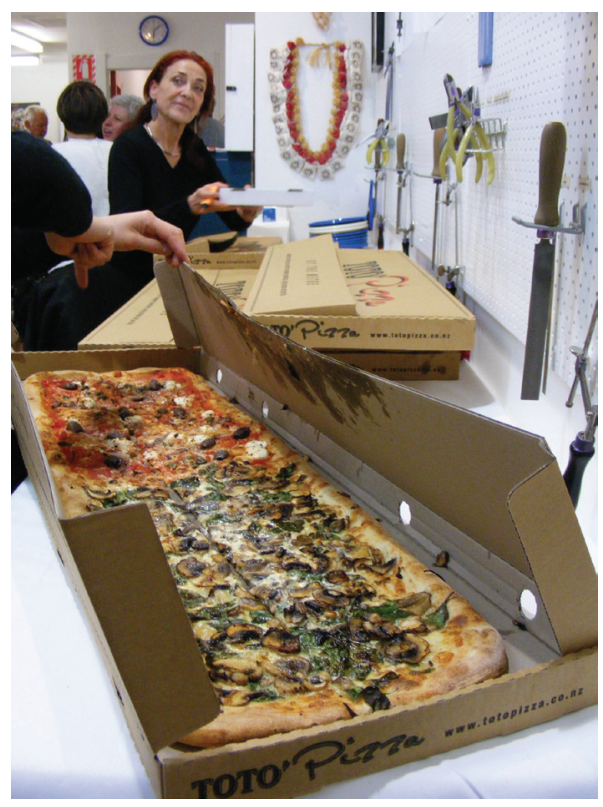

Figure 3. Sharing pizzas at Whau Studio: "Five metres of pure joy."

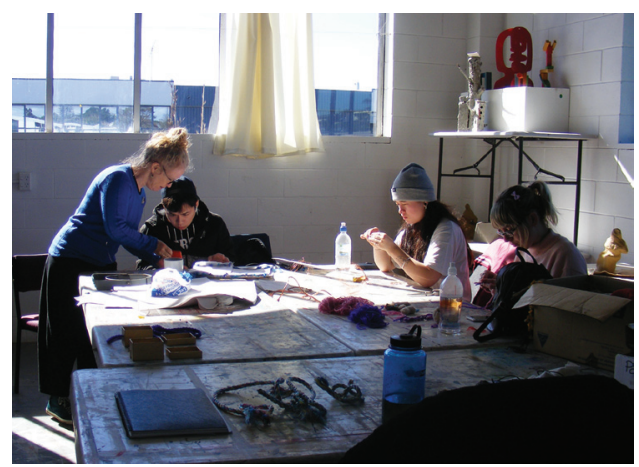

Figure 5. CLINKers making at Hungry Creek Art and Craft School.

The makers of Fishing Net, Plastic Bag Backpack, Bag yourself a Box and Kete Kuku all used waste plastic from businesses within walking distance of the school, while the makers of Synthetic Swarm and STOP!Poverty used waste plastic from the wider area. The CLINK makers chose to highlight the environmental impact of waste on the ocean, to transform the waste material from a useless state to a useful one and to acknowledge the history of the waterfront as a place for food gathering. 


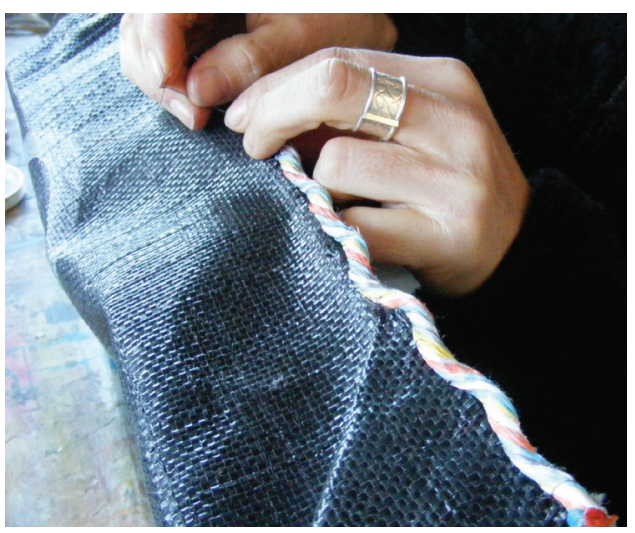

Figure 6. Rachel, Plastic Bag Backpack, skip-sourced polypropylene fabric and cord.

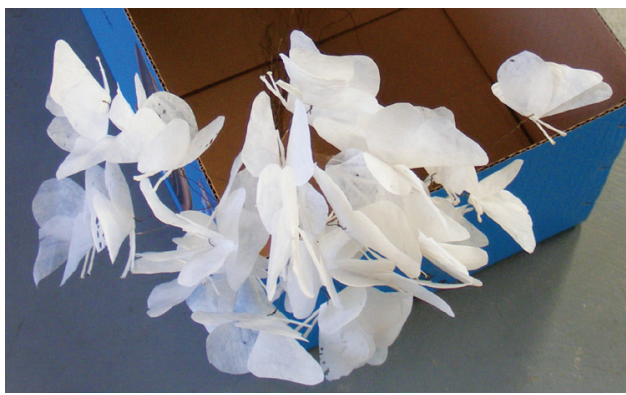

The plantings along the Auckland waterfront have been selected to act as 'life rafts' for species arriving on the urbanised coast. Two New Zealand butterflies are being encouraged to settle here, the common copper and the New Zealand red admiral, to help promote ecological and biodiversity values across the Wynyard Quarter and the wider waterfront.

\section{Lissy}

My first approach to the project was to unwind any mounting pressure to produce an exquisite object in a limited amount time by stepping back and observing the group until they were no longer strangers to me.

With one making day, I set out to create a small, precious, vessel using a cage-like structure already familiar in my studio work. To manage existing employment commitments with the fast pace of CLINK, I was encouraged to collaborate on artworks already underway by Johanna. This resulted in the series Resonant Chambers, a collection of egg-like objects with wire constructions protruding from the forms. Our dialogue through shared making developed the works forward from both our original intentions to become a fabulous and curious set of works. This first-time maker's collaboration for me was exciting.

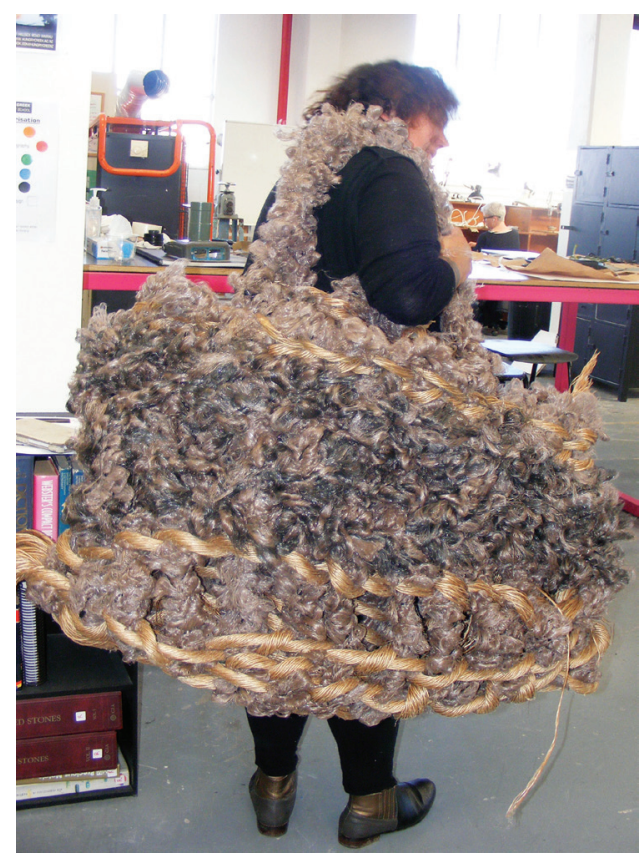

Figure 7. Metiria, Kete Kuku, mussel farm rope.

Figure 8. Michelle, Synthetic Swarm, single-use shopping bags and wire.

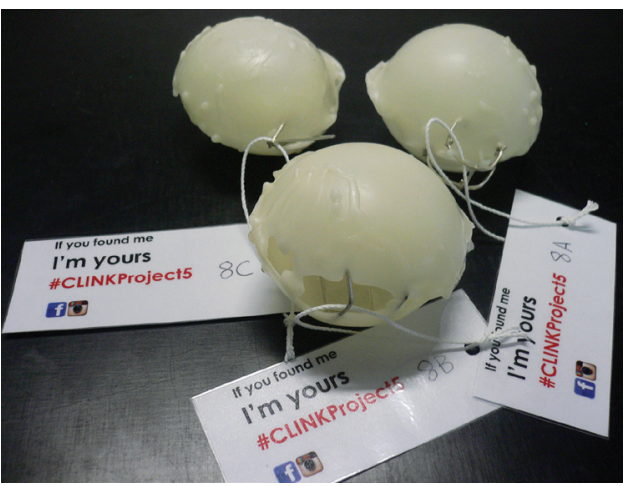

Figure 9. Johanna Zellmer and Lissy Hunt, Resonant Chambers. 


\section{Andrea M}

My first time working within the CLINK collaboration was an exciting experience, exchanging the comfort of repetition, order and the pre-planned development of ideas and materials for designing an object out of an assortment of materials never seen before, using whatever I had in front of me. An assortment of boxes were placed on a table and my heart skipped a beat at the concept of rummaging through boxes I had never seen before to find a variety of materials and treasures. I found some old boxes, various chains, beads and plastic-like materials covering the table in front of me and I admired all the sparkly metallic things that I could put together. Quietly developing my own interpretation of the bag, I considered what materials I could put together to create some unique bags objects that weave intriguing ideas, but also appear as one-of-a-kind.

\section{EVENT DAY (LOST AND FOUND)}

\section{Rachel}

I think it would be fair to say that the day began with a certain degree of apprehension within the group. The weather forecast was telling us that we were destined to end up as drowned rats, and we were uncertain how the exhibiting was going to pan out. Thankfully, these concerns quickly subsided when passers-by were delighted to stumble upon some treasures, which brightened up their day. The joy generated from giving and receiving rippled through the group. Personally, I was delighted to hear that the man who had earlier fueled us with some of the best bacon butties ever scored my Plastic Bag Backpack. Apparently, he was gifting it on to a friend, but I had faith that it was going to be used and treasured. Job done.

\section{Eilish}

The day of the Lost and Found CLINKProject5 event, I walked around looking for a suitable place for my Merbaby work to reside while it waited to find its forever home. I felt nervous about leaving Merbaby exposed to the elements of wind and rain, tucked into the corner of a green planter box, covered in shell segments down by the Auckland Waterfront Viaduct. After leaving Merbaby and hoping that the public would interact with our Lost and Found objects, I

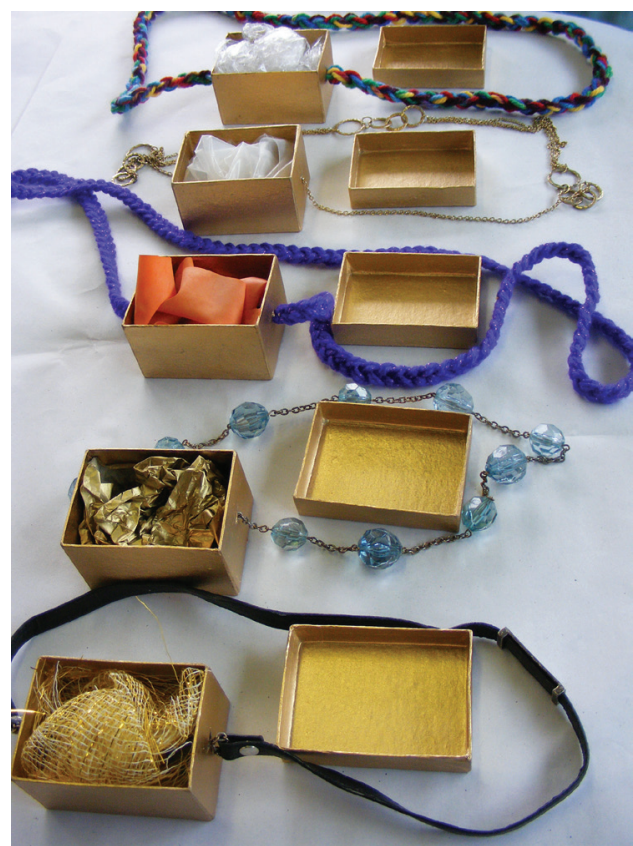

Figure 10. Andrea.

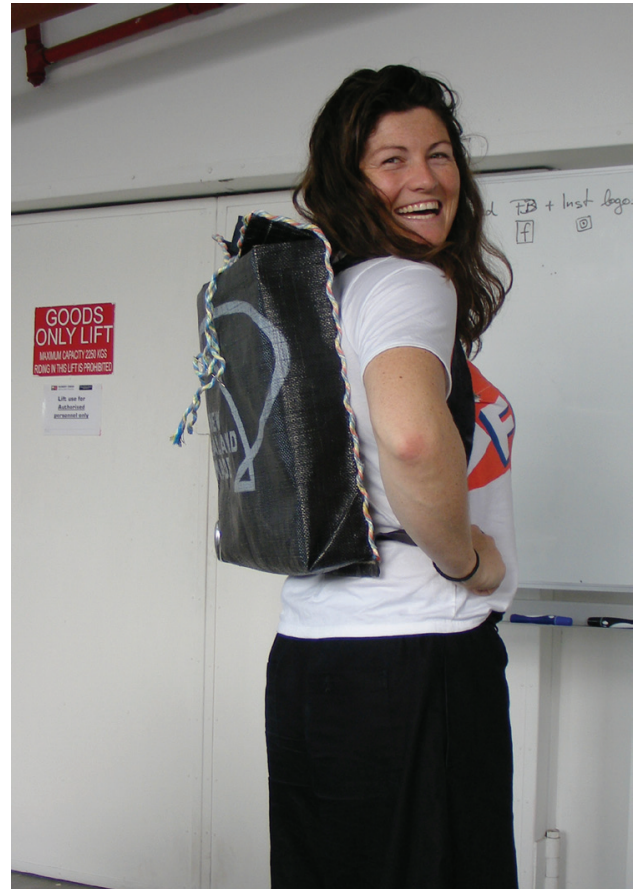

Figure II. Rachel, Plastic Bag Backpack, skip-sourced polypropylene fabric and cord. 
spotted a young boy carrying Merbaby away with his father. In a hurry, I called out that I had made the piece and was so excited someone wanted to take Merbaby home with them. I was delighted to hear that the young boy was taking the piece home for his little sister. My heart felt so full - I had created something to gift to the public and they had accepted it and given Merbaby a home. The story of Merbaby and the CLINKProject5 collective will continue on in the lives of those who found our lost objects.

\section{Haonan}

CLINKProject5 was my second time participating in CLINK, and it was very different to the last time. The event-day theme was 'plastic-free.' It was rather windy, so unfortunately my project was damaged while I was venturing along the waterfront, but I fixed it and then later relocated it to a more favourable location. To begin with, I asked international audiences to sign "Plastic-free" in their own language on my project. In the end, I collected six languages - Chinese, Russian, English, German, French and Korean. I hung up my project on a big blue umbrella and some people appeared very interested in it. The materials I used meant the work was very fragile and not really suitable for being outside in the inclement weather. Therefore, I decided to move my project inside the library and display it there for the rest of the day with the intention of encouraging more people to stop using plastic. I hid another object, A Glue Handbag, in the ferry ticket office. A commuter found it when he was going on a work trip and took it with him as he said it would make a lovely gift for his child.

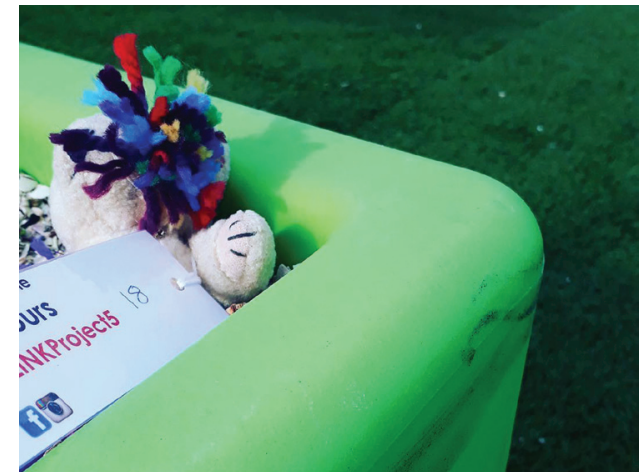

Figure 12. Eilish, Merbaby.

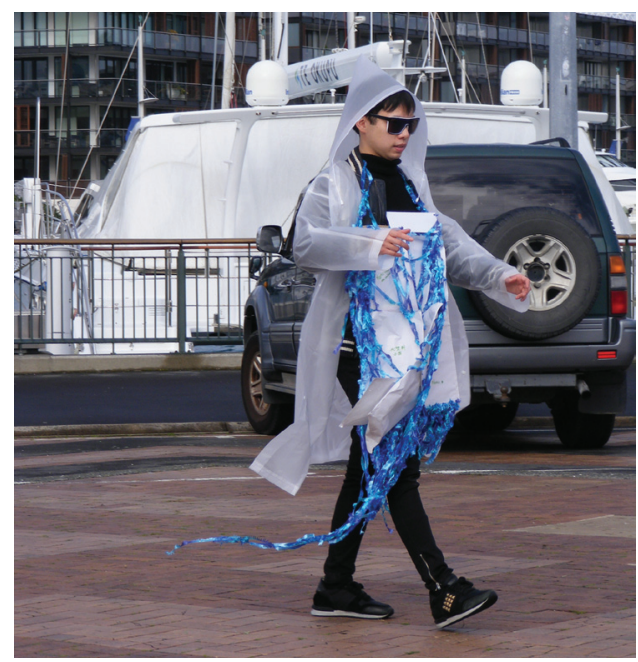

Figure 13. Haonan, Plastic-free.

\section{Andrew}

In the five days since the scouting mission, the group had resolved a scheme to make work in response to the site and ways to bring that work to an audience of visitors to the Viaduct.

Everybody placed or hid their work somewhere on site. We generated an audience via Facebook promotion, but also hoped that random visitors might notice the work, look at the attached ID tag and take the work away as new finders and keepers.

Arriving on site on the day, I was relieved to find the weather less catastrophic than the forecast.

I made a linked set of eight full-size maritime flags that could also function as reusable shopping bags. The coded flags spelled out the message "Stop Poverty." My ideal was to hoist the flags up the mast of a superyacht. I targeted Global M, a \$50 million Euro ketch. I approached the yacht's engineer who was sympathetic, but wanted me to speak to the captain, Marcus. While waiting for that opportunity, I tied the flags to the railing nearest to the yacht. 


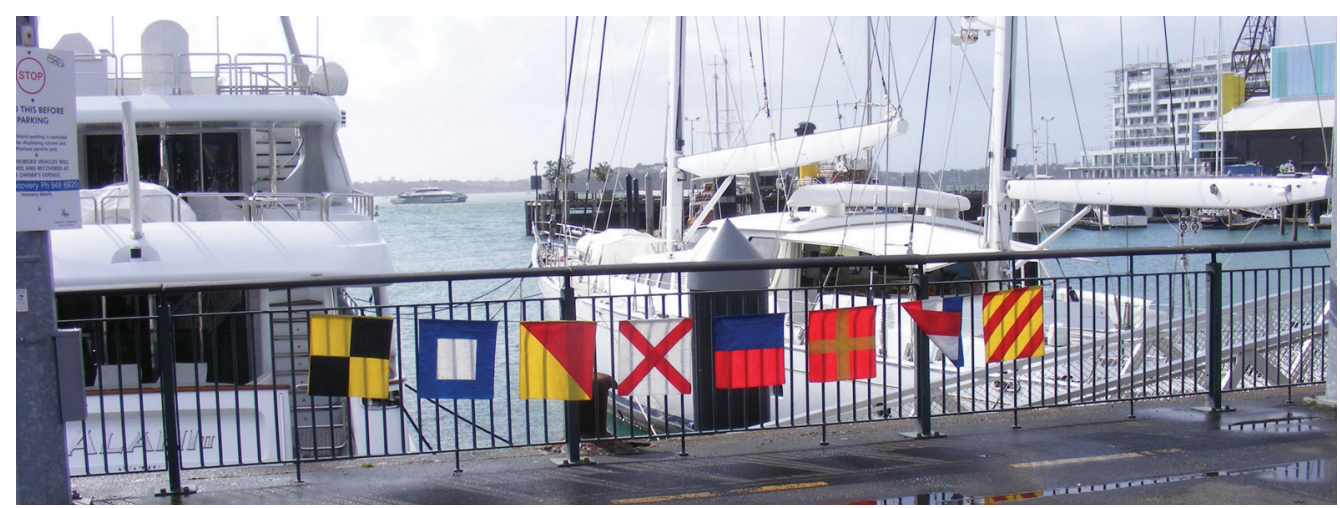

Figure 14. Andrew, Stop Poverty.

They worked beautifully, adorning the site with colourful flags fitting right in with the maritime environment. The ironic message was only able to be read by marine professionals - a sailor on a nearby yacht asked me what L-POVERTY meant. He later gave me a printed sheet of parody codes taking the piss out of the real meanings.

Eventually, Rosie, a traveler from the UK found and claimed my flags. Rosie became aware of CLINK when she met the Clink crew staying at the same backpacker accommodation. I was fortunate to meet Rosie and swap stories. She told me she would send the flags home to her mum in Jersey. Rosie was stoked - me too.

\section{WRITING}

The final activity of the CLINK project was a day devoted to writing with the aim of generating this collated journal report. Participants formed subgroups and followed a similar methodology (individual/ collaborative/collective work) to the making event to generate a resource of text. We brought the project full circle by gathering again at Objectspace in Ponsonby.

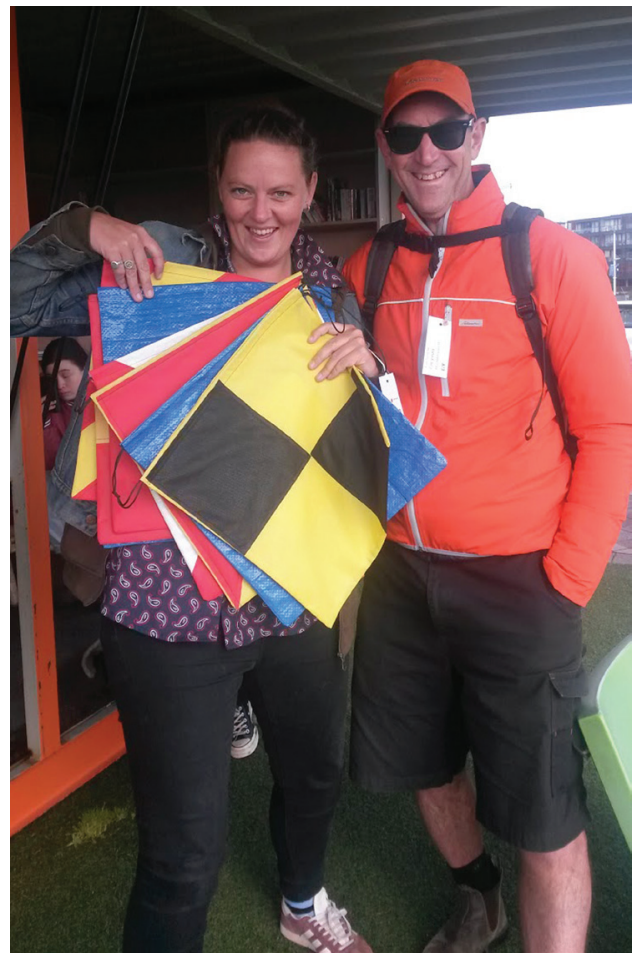

Figure 15. Andrew and Rosie, who eventually claimed Andrew's maritime flags.

Yulia

From the outset of CLINKProject5, all the participants significantly valued the collaboration and active experience involved in working in a group. The inclusion of all our voices through each 'step' of the project was important. It allowed for decision making to be arrived at collectively. The voice of each member of the group, whether student or staff, in the space of CLINKProject5 was heard, bringing together a multitude of experiences. This space, both inside and outside the educational system, provided a real-world art experience. 
Secondly, the development of relationships between the public and artists was of equal value to the experience of shared making. Connecting with the audience - stating that we are here and that we care - was an experience that stayed with me after Lost \& Found was shown.

\section{Anataia}

CLINKProject5 was my second time experiencing the collaboration between the Dunedin School of Art and the Hungry Creek Art and Craft School.

The continuation of past relationships between the experienced CLINKers, and the new relationships formed with the first-timers, was an awesome outcome which led to the collaborative making process becoming a very relaxed and fun experience. The enormous amount of laughter and chatting involved helped with many stressful moments. As for my making process, it was a slow and tedious job, but the quality chatter and cheeky bakery breaks helped with the long hours of winding and stitching materials.

\section{Yeonjoo}

People gathering to create pieces to speak to the public of Auckland. The studio busy and bustling; looking and sharing; hands moving and eyes focused. As more hands become busy, the more pieces of work are born. It's not just the pieces that are made, but the relationships between the makers, feeding each other with ideas and suggestions, with comments and compliments. Making as a single person, but working as collective, all creating for a single goal: to communicate and interact with the public.

There was comradeship between the people from Dunedin and the people from Hungry Creek. While some were first-timers in CLINK and others for the nth time, everyone was in the same situation and under the same pressure to create in the time given - to create their own voice within their piece. It was not just the pressure that brought the creators together, but also the down time, opportunities to gather and share food and thoughts and get to know one another.

- For more on CLINKProject5, see https://www.facebook.com/clinkproject/

- Instagram: ClinkProject5

- https://www.op.ac.nz/study/creative/art/

- https://hungrycreek.ac.nz/

- \#plasticfree

- Look for CLINKProject6 at Radiant Pavilion, Grainger Museum, Melbourne, I2-I5 September 20 I9.

I Benjamin Lignel, "Made Together: Thrills and Pangs of Participatory Jewelry," Art Jewelry Forum, 28 June 2016, https:// artjewelryforum.org/made-together.

2 Ministry for the Environment, Proposed Mandatory Phase out of Single-use Plastic Shopping Bags: Consultation Document, 20 I 8 , https://www.mfe.govt.nz/sites/default/files/media/Waste/plastic-bags-consultation-doc.pdf. 